\title{
Damage and deformation in composite sandwich panels exposed to multiple and single explosive blasts
}

\author{
H. Arora \\ Department of Bioengineering, Imperial College London, SW7 2AZ, UK \\ P. Del Linz \\ School of Civil and Environmental Engineering, Nanyang Technological University, \\ 639798, Singapore \\ J. P. Dear \\ Department of Mechanical Engineering, Imperial College London, SW7 2AZ, UK
}

\begin{abstract}
The blast resistance of glass-fibre reinforced polymer (GFRP) sandwich structures has been investigated for increasing shock intensity and for multiple blast exposures. In this study, sandwich panels of $1.6 \mathrm{~m} \mathrm{x} 1.3 \mathrm{~m}$ were subjected to $30 \mathrm{~kg}$ charges of $\mathrm{C} 4$ explosive at stand-off distances from $8 \mathrm{~m}$ to $16 \mathrm{~m}$. These targets formed part of two studies presented here: one, to observe the loading of the same geometry of target to an increasing shock intensity; and the second, to observe the response of one target to multiple blast impacts.

Experimental data provides detailed data for sandwich panel response, which are often used in civil and military structures, where air-blast loading represents a serious threat. High-speed photography, with digital image correlation (DIC), and laser gauge systems were employed to monitor the deformation of these structures during the blasts. The experimental data provides for the development of analytical and computational models. Initial analysis of the blast experiments are presented alongside a finite element model to establish trends in deformation behaviour. Details of failure mechanisms and the conditions for the onset of failure are also discussed.
\end{abstract}

Keywords: Sandwich structures, Glass-fibre reinforced polymer (GFRP), Air-blast 


\section{Introduction}

Recent advances in composite manufacturing have occurred predominantly in the aerospace, marine, automotive and related industries. Whereas, formerly, naval vessels were constructed from steel, composites provide a significant weight reduction and increase in stealth characteristics whilst maintaining high strength properties. In a military environment, composite materials can be subjected to increasingly demanding and varied conditions during service. Specifically, blast loading represents the most extreme threat to a structure. Materials testing under blast is now becoming more common in the literature due to the unfortunate rise in use of explosive devices in civilian environments as well as in direct military combat. Materials evaluated in the open literature range from fibre reinforced composites $[1,2]$ to concrete [3] to glazing structures $[4,5]$ amongst others $[6,7,8]$. Larger scale blast experimentation open in the public domain tends to be limited to concrete and retro-fitting concrete for increased blast tolerance $[9,10,11]$.

Numerous investigations have been performed into the dynamic deformation of plates due to explosive blast loading [12, 13, 14, 15] with many summarised in [16]. This area remains of key study given the large number of variables at play in blast scenarios that need to be characterised. Menkes and Opat [15] classified the failure modes of structures under impulse loading, from large inelastic deformation to tearing and shear failure at the supports. Neuberger observed the effects of air-blast [17] and buried charges [18] on clamped circular plates and the validity of scaled testing for the comparison of similar blast events using different explosive mass and stand-off distance. This work was extended with the use of image correlation methods to quantify panel distortion during buried [19] and open-air blasts [20]. Nurick, Olsson et al. [21] further investigated the failures described by Menkes and Opat. Of particular interest to these researchers were the effects of the boundary conditions for the purpose of predicting tearing in steel plates [22]. Many studies have extended this research to the analysis of composite plates under blast loading [23, 24, 25, 26, 27].

Given the high costs and space requirements for explosive testing, shock tubes offer a cost-efficient and effective alternative for scaled experiments. Shock tubes of various shapes and sizes are often used to replicate explosive effects [28] on various materials from structural [29, 30] to even biological materials [31]. Shock tubes enable a shock load to be produced in a controlled manner. Additionally the experiment can focus solely on the shock wave in- 
cident rather than other factors inherent in blast situation, e.g. burning. A shock tube consists of a long cylinder, divided into a high-pressure driver section and a low pressure driven section, which are separated by a diaphragm. To create a shock wave, the driver section is pressurised until the pressure difference across the diaphragm causes it to rupture. This rapid release of gas creates a shock wave, which travels down the tube to the test specimen [32]. Studies into the shock loading of composite materials and sandwich panels have been continually developed to great effect [33, 34, 32, 35, 36, 37]. Parameters such as the distribution of blast energy during impact [36] and performance of composites subjected to sequential impact and blast loading [35] have been investigated.

The research presented here builds on previous findings focussing on fullscale air-blast experimentation conducted on GFRP sandwich composite panels $[20,38,39]$. Although sandwich structures remain a significant area of research [40, 41], there is a lack of large-scale experimental data, publicly available in this field, for full-scale explosive testing on composite materials. Therefore, large scale data and current, modern approaches applied to data acquisition are an important contribution to this field of research. The experiments were carried out at a specialised test facility, located at RAF Spadeadam, Cumbria,UK. A total of five explosive charges each $30 \mathrm{~kg}$ C4 (38.4 kg TNT equivalent) were tested over a range of stand-off distances (8$16 \mathrm{~m}$ ) against three targets (with repeat blasting of one of the samples). The aim of these air-blast experiments was to capture displacement-time histories of the sandwich composite panels and understand how damage develops during a given blast event. Two methods were employed to obtain these displacement-time histories. High-speed 3D digital image correlation (DIC) was employed to capture full-field displacement plots of the rear surface of the targets. Point displacement measurements were taken during some experiments using a laser gauge arrangement to, firstly, verify the results obtained from the DIC analysis for point measurements, as well as being used as a stand-alone system. The experiments represent the face sheets of a ship's hull present above the waterline, which could be subject to surface or openair blasts. These experiments provide full-scale data to validate analytical and numerical models of such structures.

\subsection{Materials}

There was one sample configuration tested, a sandwich composite panel, shown schematically in Figure 1. Sandwich composite materials were provided 
by SP Gurit manufactured by P.E. Composites.

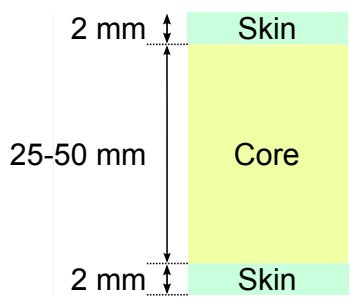

Figure 1: Schematic diagram of the sample panel design and dimensions.

All three panels had the same GFRP skins constructed using 2 plies of $0^{\circ} / 90^{\circ} / \pm 45^{\circ}$ E-glass quadriaxial skins (code: QE1200) on a $40 \mathrm{~mm}$ thick styrene acronitrile (SAN) foam core (code: P800). The sandwich constructions were then infused with an epoxy resin (Ampreg 22). A summary of the quasistatic properties of the skin and core materials are given in Table 1 . The exposed target area for the air-blast experiments was $1.6 \mathrm{~m} \times 1.3 \mathrm{~m}$. These large panels were designed to represent full-scale face-panels of comparable scale to real naval structures. These targets were bonded into steel frames prior to testing, ready to be secured to the test cubicle (see Section 1.2).

Table 1: Material properties of the sandwich panel constituent elements [42].

\begin{tabular}{lll}
\hline Material property & QE1200 & P800 \\
\hline Density $\left(\mathrm{kg} / \mathrm{m}^{3}\right)$ & 1750 & 155 \\
Tensile modulus (GPa) & 17 & 0.14 \\
Compressive modulus (GPa) & - & 0.13 \\
Tensile strength (MPa) & 260 & 2.85 \\
Compressive strength (MPa) & 200 & 2.8 \\
Shear modulus (MPa) & 6500 & 61 \\
Tensile failure strain (\%) & 1.5 & 2.2 \\
\hline
\end{tabular}

The test samples were designed to withstand a peak (reflected) shock pressure, $P^{\max }$, of $200 \mathrm{kPa}$ without catastrophic failure. Methods used to design these structures involved both analytical and computational methods, as previously outlined in [20,39]. A finite element model was generated in ABAQUS/Explicit 6.10. This model comprised of a continuum shell element model sectioned into the various layers of the sandwich composite (i.e. skin and core) with the material properties (density and Young's modulus) as 
given in Table 1. This was then subject to a triangular pressure pulse, with zero rise-time to $P_{\max }=200 \mathrm{kPa}$, uniformly distributed over the entire plate with a linear decay time of $5 \mathrm{~ms}$. It was shown that using a simple elastic material model and reducing the load conditions to a uniform pressure pulse with ideal fully clamped boundary conditions that the plates (configuration as illustrated in Figure 3) would produce a peak central displacement in the region of 45-65 mm for targets with a range of core thicknesses of 30-50 mm (producing strains in the GFRP below their expected failure strains $\sim 1.5 \%$ ).

Based on this model a series of targets were manufactured and various blast scenarios were tested. The charge weight $(W)$ was chosen to simulate moderate to large blast loads in close proximity to naval vessels above the waterline. Here, $30 \mathrm{~kg}$ charges of C4 (38.4 kg TNT equivalent) were used for the testing on samples over a range of stand-off distances $(R), 8-16 \mathrm{~m}$. The experiments conducted for a $30 \mathrm{~kg} \mathrm{C} 4$ charge at a $14 \mathrm{~m}$ stand-off distance, i.e. an equivalent $P^{\max }$ of $\sim 200 \mathrm{kPa}$, were designed in line with the analytical and numerical models. This experiment was used as a reference for a transition from elastic response to visible damage initiation and failure of the targets. Whereas the tests conducted with a $30 \mathrm{~kg} \mathrm{C} 4$ charge at $8 \mathrm{~m}$ was designed with the intent to cause significant visible damage. Explicit damage modelling was beyond the scope of this study but the elastic model showed good correlation with basic deformation characteristics within this test frame for the range of stand-off distances explored here [20].

\subsection{Air-blast test design}

A test arrangement is given in Figure 2 featuring all external instrumentation that was used during all air-blast tests. In each case the spherical charge was raised off of the floor to the mid-height of the target and positioned at the centre of the test pad at the given stand-off distance from the target. The test pad is approximately $100 \mathrm{~m} \times 100 \mathrm{~m}$ in area and is made of concrete, the charge is positioned on a $150 \mathrm{~mm}$ thick steel plate to avoid cratering during blast.

The test fixture was a steel test cubicle, which was used to test one sample at a time against a $38.4 \mathrm{~kg}$ TNT equivalent charge, although up to two test samples can be attached at one time in this fixture. Analysis of these blast experiments was split into two studies evaluating: single blast loading of sandwich panels; and multiple blast loading of sandwich panels. This clamping condition is meant to represent the support a free-spanning section of composite material may experience when mounted in a real structure. The 

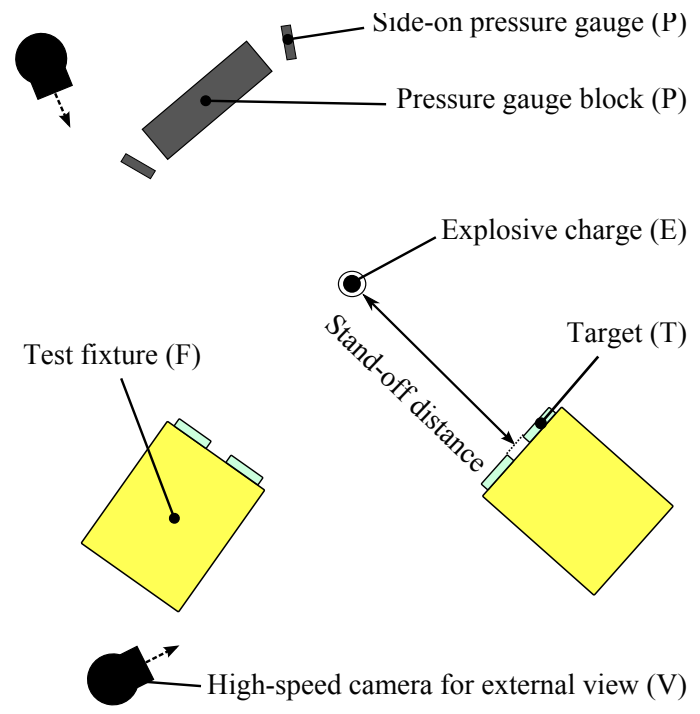

Figure 2: Blast configurations showing a schematic diagram of the test set-up.

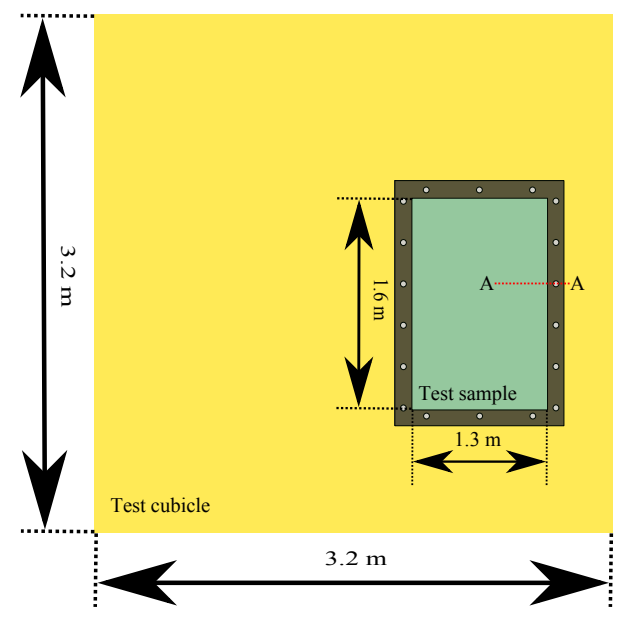

Section A-A

Figure 3: Schematic of sandwich panel mounting fixture.

reality is there are a vast number of support structures and configurations that can be examined [43]. Moreover support conditions on blast experiments, although ideally clamped or built-in, will deviate due to the energy delivered to the finitely rigid (stiff) target structure. Therefore as robust a support structure as possible with regular clamping along the supporting edges, through reinforced bolt-holes, was chosen for ease of repeatability and 
universal discussion.

\subsubsection{Single blast loading of sandwich panels}

From the set of samples, three samples each with $40 \mathrm{~mm}$ thick core (G40a, G40b and G40c) GFRP sandwich panels were subject to three separate 30 $\mathrm{kg}$ charge $\mathrm{C} 4$ explosions at $16 \mathrm{~m}, 14 \mathrm{~m}$ and finally $8 \mathrm{~m}$ stand-off distances. This investigation was designed to represent a real combat scenario, where different areas of the ship surface may be subject to a number of different blast conditions of differing severity. For this analysis full-field displacement and in-plane principal strain data of the deforming panels and pressure data was recorded for the duration of the event.

\subsubsection{Multiple blast loading of sandwich panels}

Similar to the investigation in Section 1.2.1, in this case however, all blasts were conducted on one sample. From the sample set, a $40 \mathrm{~mm}$ thick core (G40c) GFRP sandwich panel was subject to two additional $30 \mathrm{~kg}$ charge C4 explosions at $12 \mathrm{~m}$ and $8 \mathrm{~m}$ stand-off distances (after the blast at $16 \mathrm{~m}$ ). This investigation was designed to represent real combat scenario where multiple strikes represent a common threat to a naval structure. Moreover the decision to progressively increase the impulse loading the sample from $30 \mathrm{~kg}$ at $16-8 \mathrm{~m}$ was based on the idea that these sandwich materials may sustain milder levels of impact from a number of far-field blasts in service prior to a severe blast. Blast loading, as an impact scenario, is not mild in any sense, however from visible inspection, which is a common method of damage detection, damage may be overlooked leading to poorer response than expected to subsequent blasts. For this analysis central point displacement and pressure data will be provided for the duration of the event. Trends in period of oscillation and peak deflections will be the focus of analysis.

A summary of all test parameters used during each investigation is given in Table 2. This table highlights: what samples were used; their basic construction; the blast parameters; and details to which investigation the test belongs. Some test data shared overlap between two investigations and these are noted in Table 2.

\subsection{Finite element modelling}

To complement the experimental data collected during the test program, a series of models was run with the aim of predicting the maximum deflections 
Table 2: Test parameters used for each test sample and an indication of which study the test data is used for: (a) single blast loading of sandwich panels; or (b) multiple blast loading of sandwich panels.

\begin{tabular}{lllll}
\hline $\begin{array}{l}\text { Sample } \\
\text { code }\end{array}$ & $\begin{array}{l}\text { Sample } \\
\text { description }\end{array}$ & $\begin{array}{l}\text { Charge weight } \\
\text { (TNT equiv. }) \\
(\mathrm{kg})\end{array}$ & $\begin{array}{l}\text { Stand-off } \\
\text { distance } \\
(\mathrm{m})\end{array}$ & Study \\
\hline G40a & $\begin{array}{l}2 \mathrm{~mm} \text { GFRP skins } \\
40 \mathrm{~mm} \text { SAN core }\end{array}$ & 38.4 & 14 & $\mathrm{a}$ \\
G40b & $\begin{array}{l}2 \mathrm{~mm} \text { GFRP skins } \\
40 \mathrm{~mm} \text { SAN core }\end{array}$ & 38.4 & 8 & $\mathrm{a}$ \\
G40c & $\begin{array}{l}2 \mathrm{~mm} \text { GFRP skins } \\
40 \mathrm{~mm} \text { SAN core }\end{array}$ & 38.4 & 16 & $\mathrm{a}, \mathrm{b}$ \\
G40c & $\begin{array}{l}2 \mathrm{~mm} \text { GFRP skins } \\
40 \mathrm{~mm} \text { SAN core }\end{array}$ & 38.4 & 12 & $\mathrm{~b}$ \\
G40c & $\begin{array}{l}2 \mathrm{~mm} \text { GFRP skins } \\
40 \mathrm{~mm} \text { SAN core }\end{array}$ & 38.4 & 8 & $\mathrm{~b}$ \\
\hline
\end{tabular}

occurring at a range of stand-off distances. The maximum and minimum distances used during the tests, $16 \mathrm{~m}$ and $8 \mathrm{~m}$ respectively, were used as limits for the numerical study as well. The models were all constructed using the commercial software ABAQUS 6.13 [44] and included both the sample panels and a representation of the support structure. The $40 \mathrm{~mm}$ core thickness panels were mainly modelled for the study, however models of $30 \mathrm{~mm}$ and 50 $\mathrm{mm}$ systems were also included for later discussion. The sample dimensions used in the experiment were replicated in the models, where therefore the exposed panels were $1.5 \mathrm{~m} \mathrm{x} 1.8 \mathrm{~m}$ in planar dimensions, with $2 \mathrm{~mm}$ thick skins on either side of the core. The full area of the sample was modelled as the boundary conditions did not display significant symmetry. The core was generally modelled with $10 \mathrm{~mm}$ solid reduced integration elements (C3D8R). The size was though reduced in the $30 \mathrm{~mm}$ core thicknesses cases to guarantee that at least four elements would be present in the thickness direction of the part. This ensured the model was able to simulate the bending of the plate accurately. Due to their low thickness, the GFRP skins were modelled using shell elements (S4R). These were of the same dimension as the core elements. this guaranteed that the nodes of the two parts would correspond exactly, therefore simplifying the tie condition imposed between them.

The support structure was modelled following the geometry of the cubicle 
used in the tests. A $3 \mathrm{~mm}$ thick, $3.2 \mathrm{~m} \mathrm{x} 1.6 \mathrm{~m}$ steel plate was therefore included using shell elements. This part was then stiffened with the inclusion of the steel UC and angle sections as per the real structure. These parts were modelled with beam elements to optimise the computational effort and were connected with the steel plate through tie conditions. Pinned boundary conditions were then assigned to the top, outside edge and bottom of the steel plate. The edge representing the middle of the cubicle was instead restrained with a symmetry boundary condition, as the two halves of structures were identical. The entire geometry of the model is shown in Figure 4.

The steel plates which were bonded to the edges of the sample were also included in the simulation and were modelled using shell elements. Again, the same size elements as the skins were used to ensure the tie condition between the parts would produce correct results. The sample construction was then connected to the cubicle steel plate part through a tie. However, to represent realistically the bond given by the bolts used in the experiment, the entire surface was not included in the constraint definition. Instead, only the nodes along the bolt lines of both the top and bottom steel plates were tied with the nodes in the same location on the cubicle shell, thus ensuring that the restraints to the sample in the model were similar to those in the experiment.

The steel parts were all modelled with a linear isotropic elasticity model. A density of $7850 \mathrm{~kg} / \mathrm{m}^{3}$, Youngs modulus of $2.0 \times 10^{5} \mathrm{MPa}$ and a Poissons ratio of 0.3 were used. The GFRP skins were instead modelled using a linear anisotropic elasticity material for fibre composites. The appropriate material parameters, as indicated in Table 1, were used as inputs to the model. Skin failure was included through a Hashin failure model [45], however failure was not expected to take place in the majority of models being run until surface strains $\approx 1.5 \%$ are attained. The parameters for the failure were obtained from Table 1, using the compressive and tensile failure limits as indicated. These were applied in both directions due to the symmetry of the plies build up. The shear limit was not available, therefore the lower compressive limit was assumed. The fracture energy was calculated with the tensile capacity and failure strain assuming a linear softening curve. Due to the lack of further information, the same energy was assumed to apply in compression and shear failures. Whilst this data was necessarily approximate, it was assumed that core failures would dominate the damage process should this take place in the models. Therefore this simpler approach for the skins was deemed appropriate in line with other modelling methods applied to sandwich beams under 


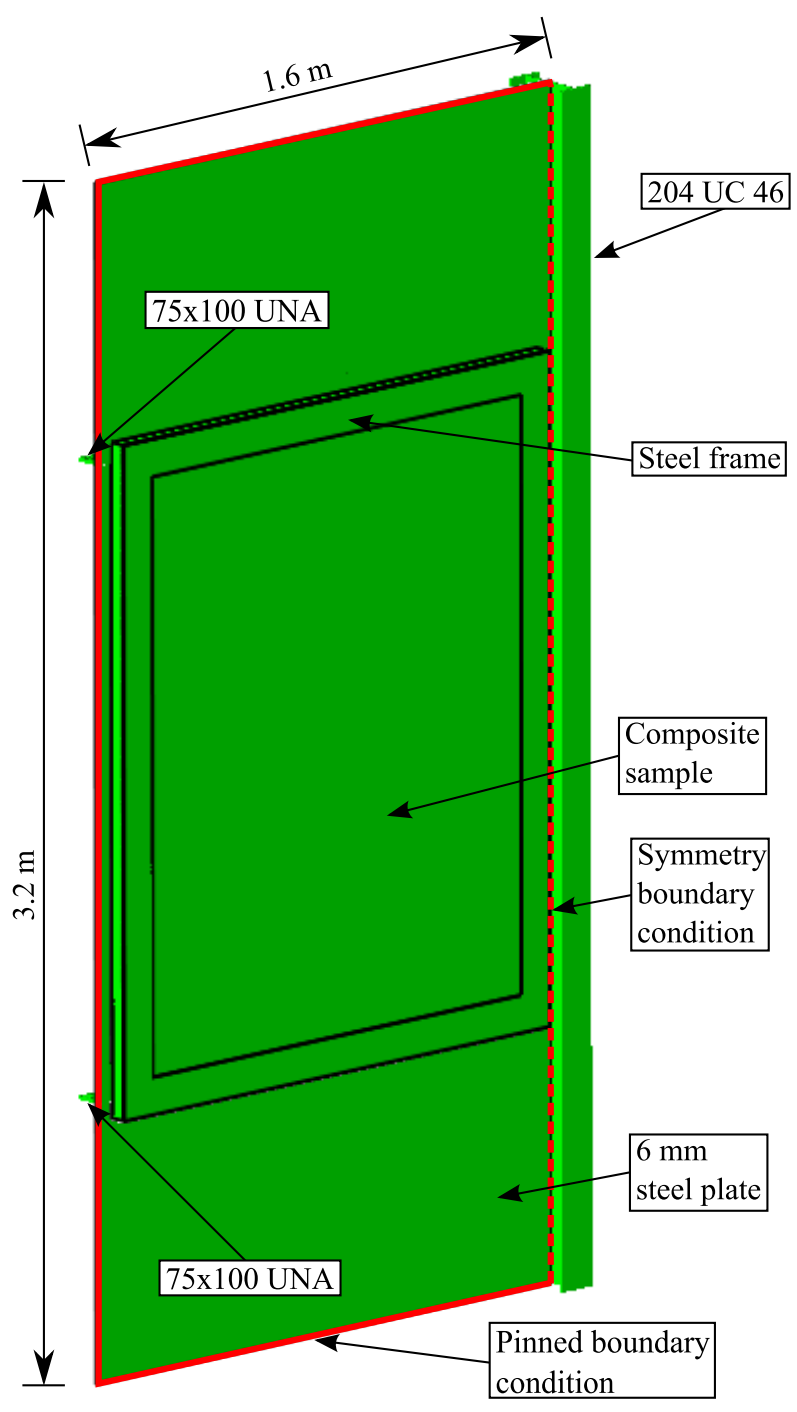

Figure 4: FEA model geometry.

impact [46]. The core material was modelled with a linear elastic material, as no significant foam compression was expected. The material parameters for this were also obtained from Table 1 . However, a brittle failure condition was included in the model. Due to strain rate effects, the tensile and compressive strength limits had to be increased. As no data was available for the specific type of foam used, the information for similar foams obtained from Kelly 
[47] were used, though they were adapted to account for the larger foam unit weight. A failure limit of $9 \mathrm{MPa}$ was therefore applied to the models.

The loading was modelled using the CONWEP module in-built in the Abaqus software. To achieve this, the charge weight and source coordinates were specified in the input file. The blast was treated as a surface blast so as to represent more closely the experimental set up. The pressure was applied to the whole structure, including the supporting steel plate. Models were run for all the stand-off distances used during tests to validate the FEA results. Additionally, five models were run at stand-offs of $15 \mathrm{~m}, 13 \mathrm{~m}, 11 \mathrm{~m}, 10 \mathrm{~m}$ and $9 \mathrm{~m}$ so as to provide deflection data for all these intermediate distances.

\section{Results}

\subsection{Progressive loading of sandwich panels}

From Study A, three samples each $40 \mathrm{~mm}$ thick core (G40a, G40b and G40c) GFRP sandwich panels were subject to three separate $30 \mathrm{~kg}$ charge $\mathrm{C} 4$ explosions at $8 \mathrm{~m}, 14 \mathrm{~m}$ and finally $16 \mathrm{~m}$ stand-off distances. Figure 5 presents the central out-of-plane displacement data from these three experiments.

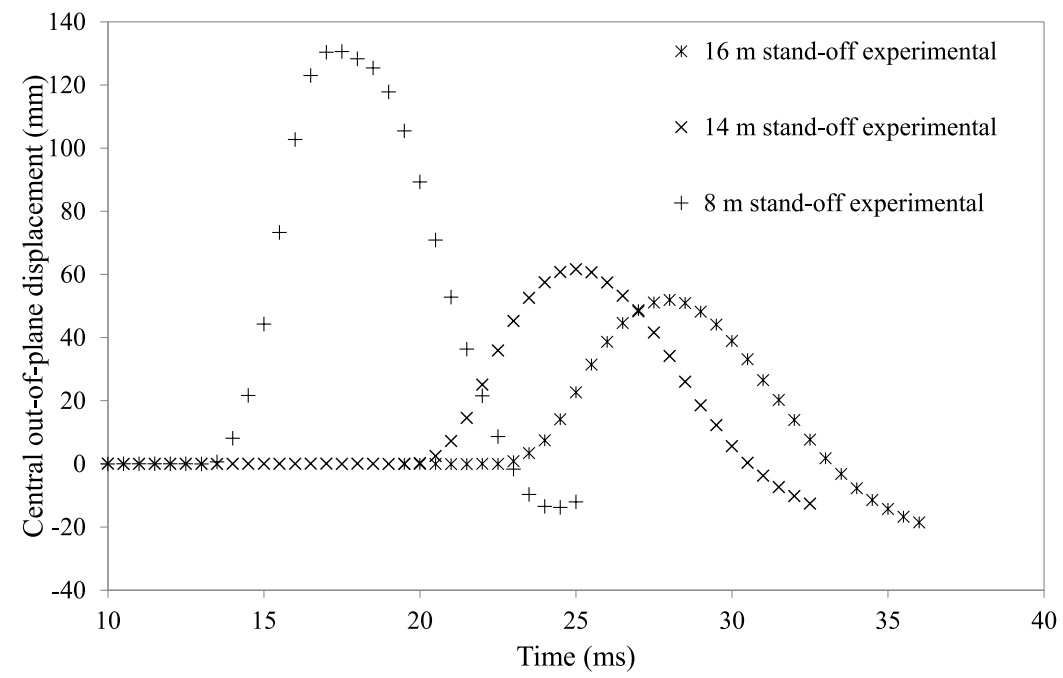

Figure 5: Summary of central out-of-plane displacement versus time for three tests conducted each using a $30 \mathrm{~kg} \mathrm{C} 4(38.4 \mathrm{~kg}$ TNT equivalent) at $16 \mathrm{~m}, 14 \mathrm{~m}$ and $8 \mathrm{~m}$ stand-off distances from G40a, G40b and G40c. 


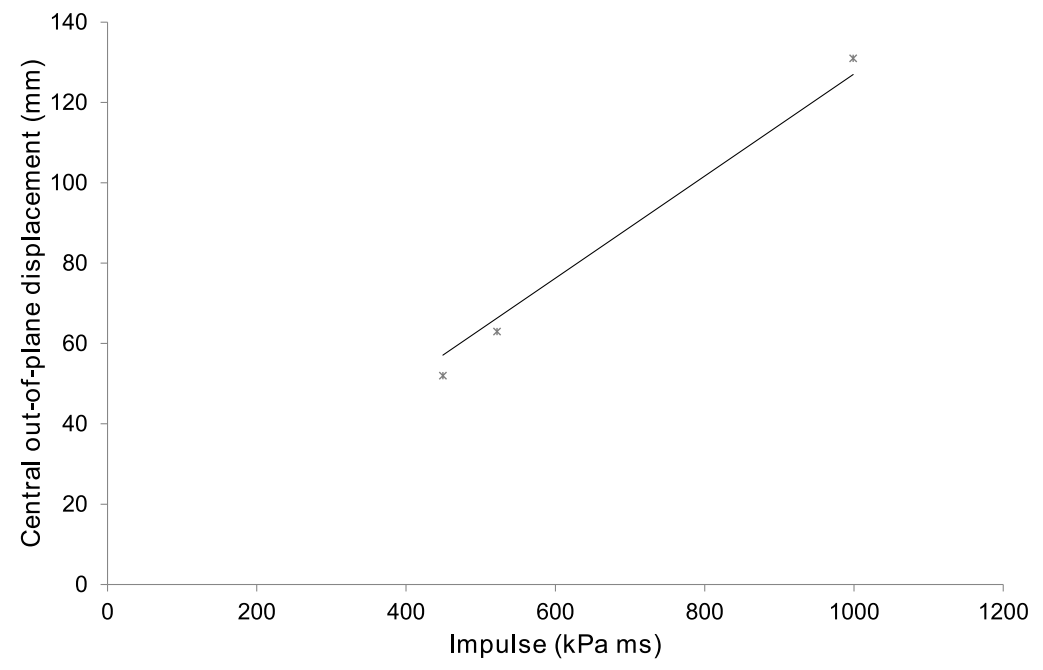

Figure 6: Plot of $U_{z}^{\max }$ against $I$ for each of the three blasts using $30 \mathrm{~kg} \mathrm{C} 4$ (38.4 kg TNT equivalent) at $16 \mathrm{~m}, 14 \mathrm{~m}$ and $8 \mathrm{~m}$ stand-off distances.

The plots highlights that, as expected, reduced stand-off leads to larger deflections. The trend of the magnitude of the out-of-plane displacement, $U_{z}^{\max }$, with respect to the reflected impulse, $I$, appears linear as shown in Figure 6. This trend was observed in reference [24], where fibre-metal laminates were subject to a range of small-scale localised blasts. Although the number of data points used here is small this trend remains visible. This trend can be misleading expecting a proportional response to an increased blast pressure load. However, provided the mode of response and failure remains constant, this is reasonable to expect. The impulse term represents the energy going into the system, therefore it is expected that the distance, that the panel (of a certain mass) would move, would increase when an increased force is applied for a longer duration (more energy input). This does not indicate any signs of how the panel deforms and whether limits are reached when modes of failure change, however this trend is clear over this test range. If the mode were to change, such as when the far-field blast becomes near-field, the failure modes may change from core-shear failure to core compressive failure. This is an alternative pathway for energy dissipation, therefore the trend would diverge from the original. 


\subsection{Multiple blast impact on sandwich panels}

This study is similar to that described in Section 2.1, however all blasts were conducted on one sample. From Study A, a $40 \mathrm{~mm}$ thick core (G40c) GFRP sandwich panel was subject to three separate $30 \mathrm{~kg}$ charge C4 explosions at $16 \mathrm{~m}, 12 \mathrm{~m}$ and finally $8 \mathrm{~m}$ stand-off distances. The first blast at a $16 \mathrm{~m}$ stand-off is summarised in Figure 7. This highlights the fact that the first blast resulted in no detectable damage being sustained. The DIC data shown illustrates the uniform deformation of the target and the fact that the response was purely elastic. This can be stated given, firstly, the smoothness and symmetry of both the forward and rebound stroke of the panel response. Secondly, the shear strain shows a very low and symmetrical progression during the response, illustrating the uniform response. Finally the magnitude of surface in-plane principal strains remained well below the failure strains (of 1.5\%). This is further reinforced by previous observations from reference [20]. Recalling experiments with both a $40 \mathrm{~mm}$ and a $30 \mathrm{~mm}$ thick core specimen, subject to blasts at a reduced stand-off distance compared to $16 \mathrm{~m}$, they suffered no visible damage [20]. The observation and conclusion from the DIC analysis here is a valid one.

The subsequent two blasts were conducted at reduced stand-off distances of $12 \mathrm{~m}$ and $8 \mathrm{~m}$ respectively. Pressure data was not available for each data set due to restrictions on data channels on the day of the test. CONWEP was employed in absence of recordings. Each of the three blasts resulted in a progressive rise in blast impulse from $I_{16 m}, 449.3 \mathrm{kPa}$ ms (predicted value from CONWEP); to $I_{12 m}, 621.6 \mathrm{kPa}$ ms (predicted value from CONWEP); to finally $I_{8 m} 1200 \mathrm{kPa}$ ms (recorded value, with $999.0 \mathrm{kPa}$ ms the predicted value from CONWEP). The response in terms of central out-of-plane deflection is plotted in Figure 8 for each blast. The laser gauge data is plotted for each. The data from these points is averaged over $0.1 \mathrm{~ms}$ intervals of data to minimise the amount of data plotted for ease and legibility of presentation. Filtering was avoided to minimise the risk of misinterpretation of the curves. It was shown previously [38] that there was close agreement between the laser gauge and DIC data for point measurement until $U_{z}^{\max }$ with some deviation present only after the $1^{\text {st }}$ rebound.

Looking at the respective curves, firstly the period of oscillation remains relatively constant, this is understandable given the fact that the mass of the system remained constant. The stiffness term remained relatively unchanged in spite of damage development. This is due to the fact that the stiffness, or $k$ term, is based around the flexural rigidity of the plate. This term is based on 


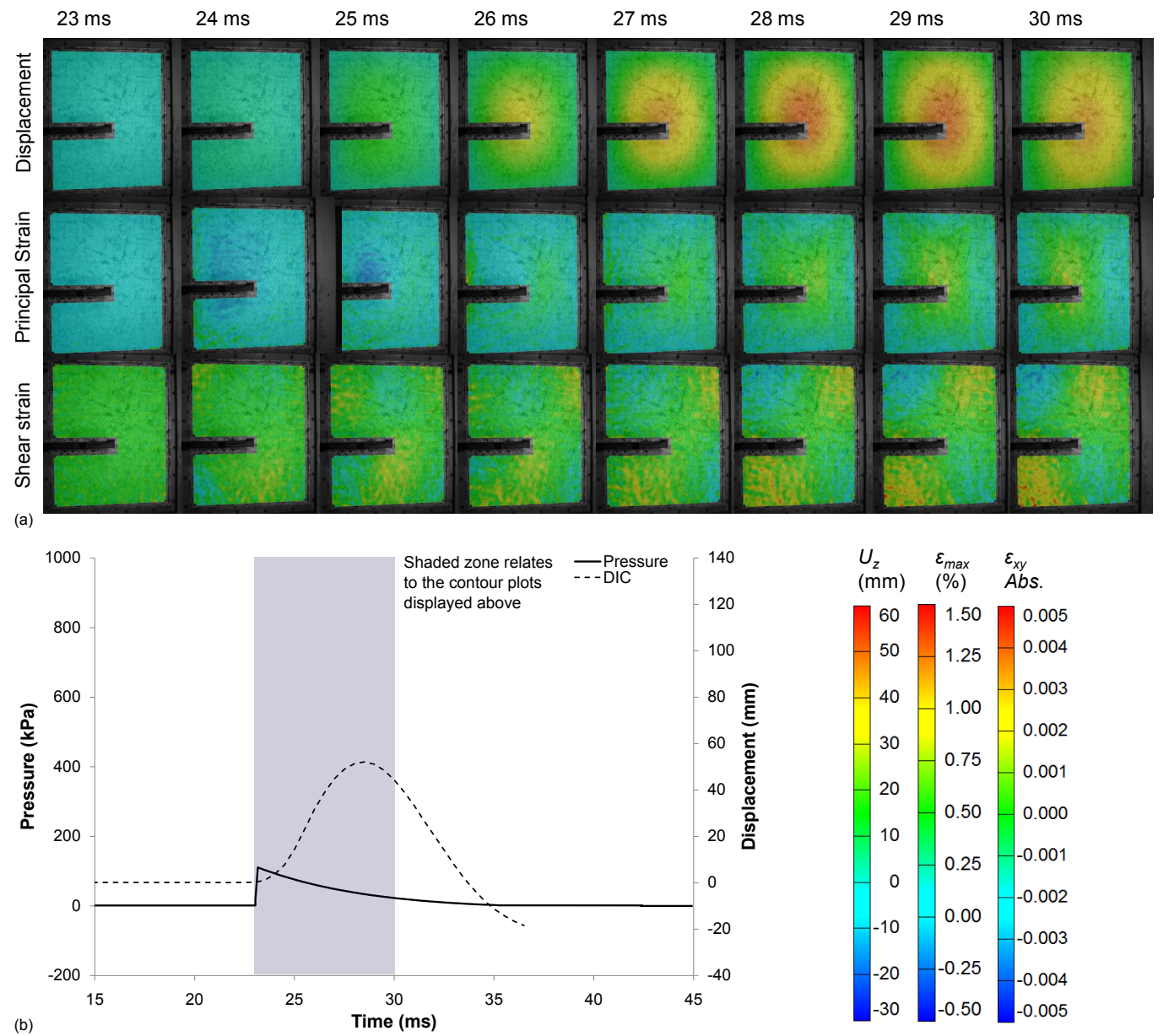

Figure 7: Blast summary for $30 \mathrm{~kg} \mathrm{C} 4$ at $16 \mathrm{~m}$ stand-off from G40c including: (a) DIC analysis and (b) a plot of pressure-time (predicted curve produced using CONWEP) and displacement-time using DIC centre point measurements. The DIC analyses features contour plots of out-of-plane displacement, maximum principal strain and shear strain, corresponding to various stages in the graphical plot. The horizontal bar visible in the contour plots (from the left hand edge to the centre) is the region of the specimen obscured by the laser gauge.

the Young's modulus of the materials, the section modulus or second moment of area and the plate geometry. The dominant failure mode in the sandwich material was core shear failure resulting in cracks forming at $\pm 45^{\circ}$ to the plate surface. The formation of these cracks on the whole still kept the core predominantly in contact with both skins until the final blast at $8 \mathrm{~m}$ stand- 


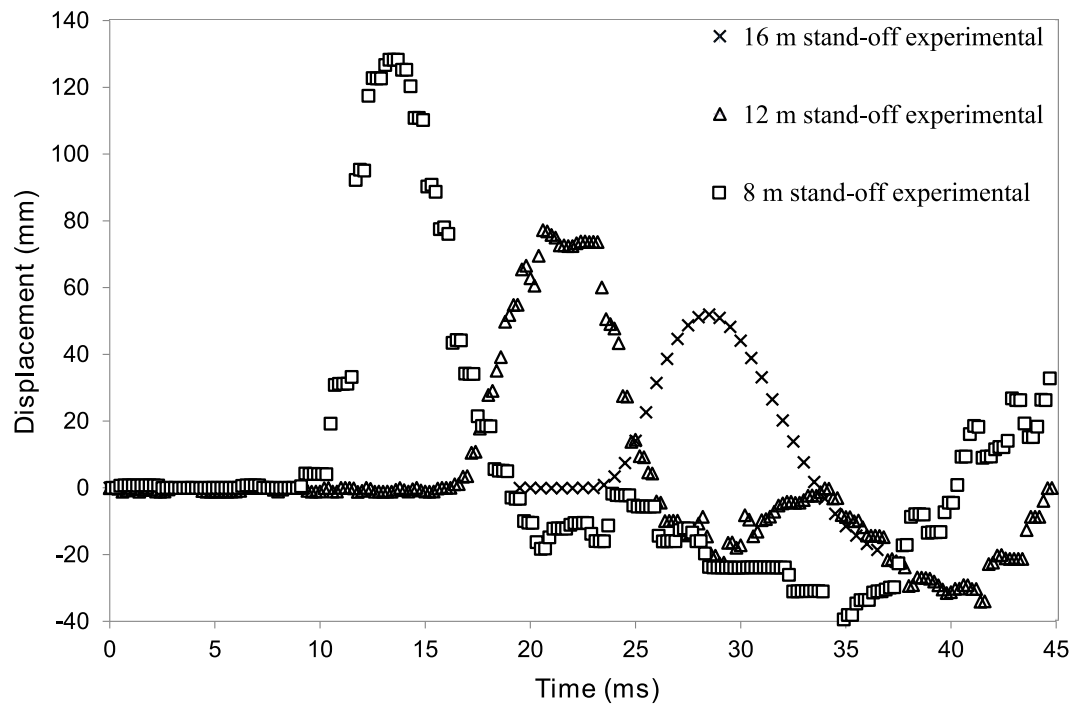

Figure 8: Summary for three consecutive tests conducted each using a $30 \mathrm{~kg}$ C4 (38.4 kg TNT equivalent) at $16 \mathrm{~m}, 12 \mathrm{~m}$ and $8 \mathrm{~m}$ stand-off distances from G40c.

off distance. This is where, in addition to front skin failures, significant interfacial failure visibly occurred with the core cracks extending through the core/skin interface. This meant that the loss in the second moment of area or section modulus remained relatively low until that point. Therefore the reduction in frequency of oscillation (increase in period of oscillation) was minimal. It was observed that the time period (half period) increased marginally from $9.5 \mathrm{~ms}$ to $9.8 \mathrm{~ms}$ from the first blast to the third. During the third blast, the skin does sustain a large skin crack, as shown in Figure 9, comprising fibre breakage and localised delaminations. However this damage occurred away from the centre and initiated at the point of rebound $\left(U_{z}^{\max }\right)$, so minimal impact was observed on the obvious reduction of stiffness that occurred with this damage formation during the blast. Furthermore, unlike G40b where the displacement plot showed clearly that a failure had occurred at $U_{z}^{\max }$, here the displacement curve is relatively smooth for the blast at 8 m. This is likely to be due to a core crack initiating during the $2^{\text {nd }}$ blast at $12 \mathrm{~m}$, therefore not resulting in any obvious deviations from a uniform forward and return stroke. Core damage initiation is explored later in the finite element analysis. Figure 10 shows the same style graph, as produced during the previous section, of $U_{z}^{\max }$ plotted against $I$. Once again this trend of proportional response to energy input is observed given mass remained 

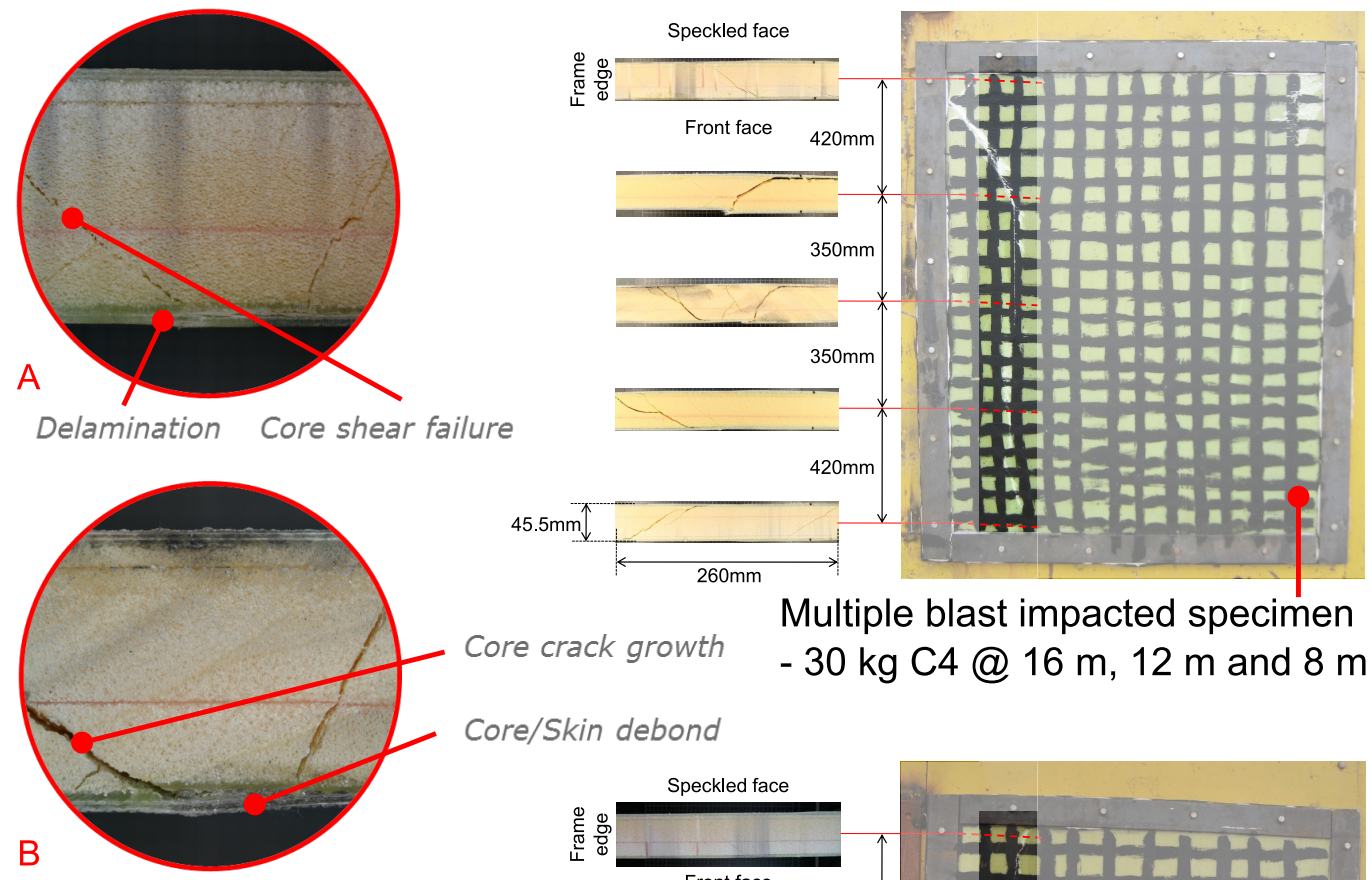

Core/Skin debond

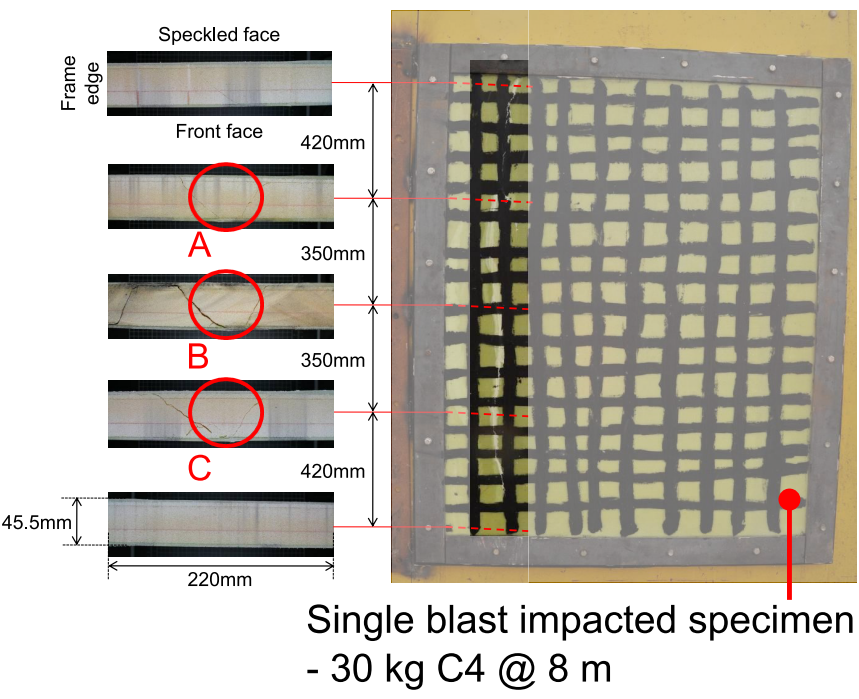

Figure 9: Damage - Front-face and cross-sectional views of two specimens: (top right) the target subject to three blasts using charge sizes of $30 \mathrm{~kg}$ at three stand-off distances of $16 \mathrm{~m}, 12 \mathrm{~m}$ and $8 \mathrm{~m}$; (bottom right) the target subject to one single blast using charge size of $30 \mathrm{~kg}$ at a stand-off distance of $8 \mathrm{~m}$; and (left) zoomed in images highlighting the various failure mechanisms present in the highlighted region of the panel, present in both specimens.

constant and the failure modes remained within the same regime (front-face and core damage). Damage is summarised for the most damaged specimens 


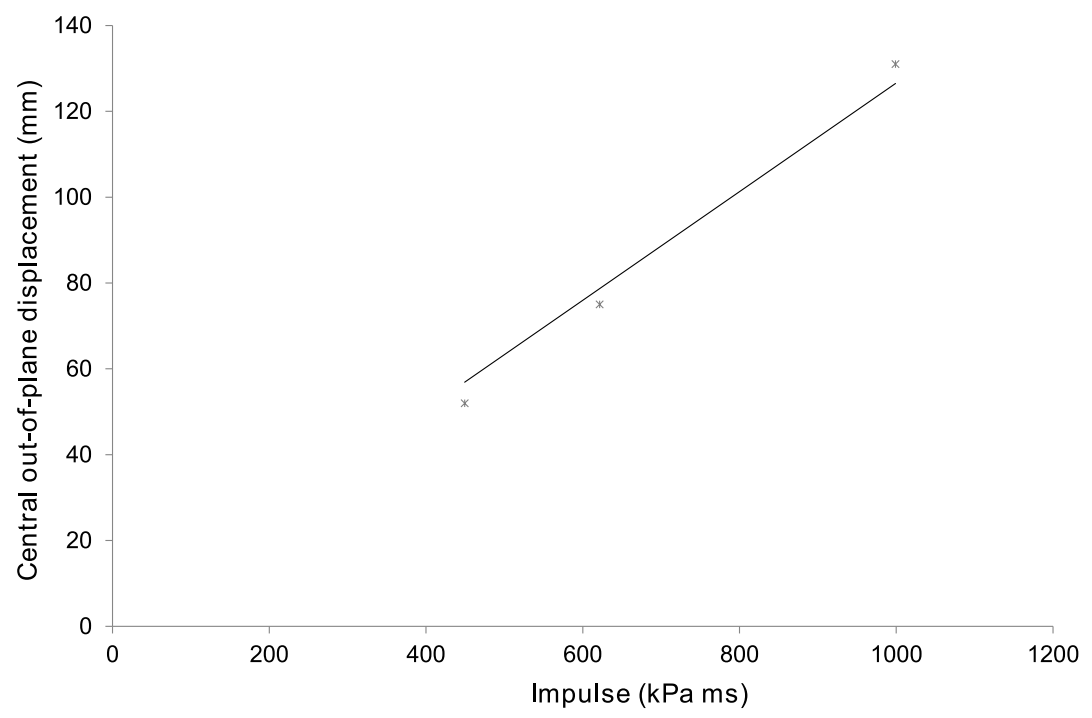

Figure 10: Plot of $U_{z}^{\max }$ against $I$ for each of the three blasts on G40c using $30 \mathrm{~kg} \mathrm{C} 4$ (38.4 kg TNT equivalent) at $16 \mathrm{~m}, 12 \mathrm{~m}$ and $8 \mathrm{~m}$ stand-off distances.

\section{in both studies within Figure 9, highlighting core and skin failures.}

\section{Discussion and analysis}

These sandwich composite structures, although very simple in construction, provided significant resistance to air-blast loading. The targets were designed to withstand a peak shock pressure of up to $200 \mathrm{kPa}$ without resulting in a catastrophic failure, and the panels attained this performance. When the charge weight and stand-off distances were altered to increase the impulse exerted on these structures, the front face and core sustained considerable damage (core cracking, formations of delaminations and skin fibre breakage). However the back face remained intact after the blast and this was consistent between each test sample.

A summary of the key results and observations from the air-blast loading of sandwich composite panels is given in Table 3. The response of the sandwich composite panels when subjected to $38.4 \mathrm{~kg}$ TNT equivalent charges over a range of stand-off distances is compared. Failures were observed in samples, particularly, when subject to blasts of a reduced scaled distance $(Z)$. These are also summarised in Table 3. 


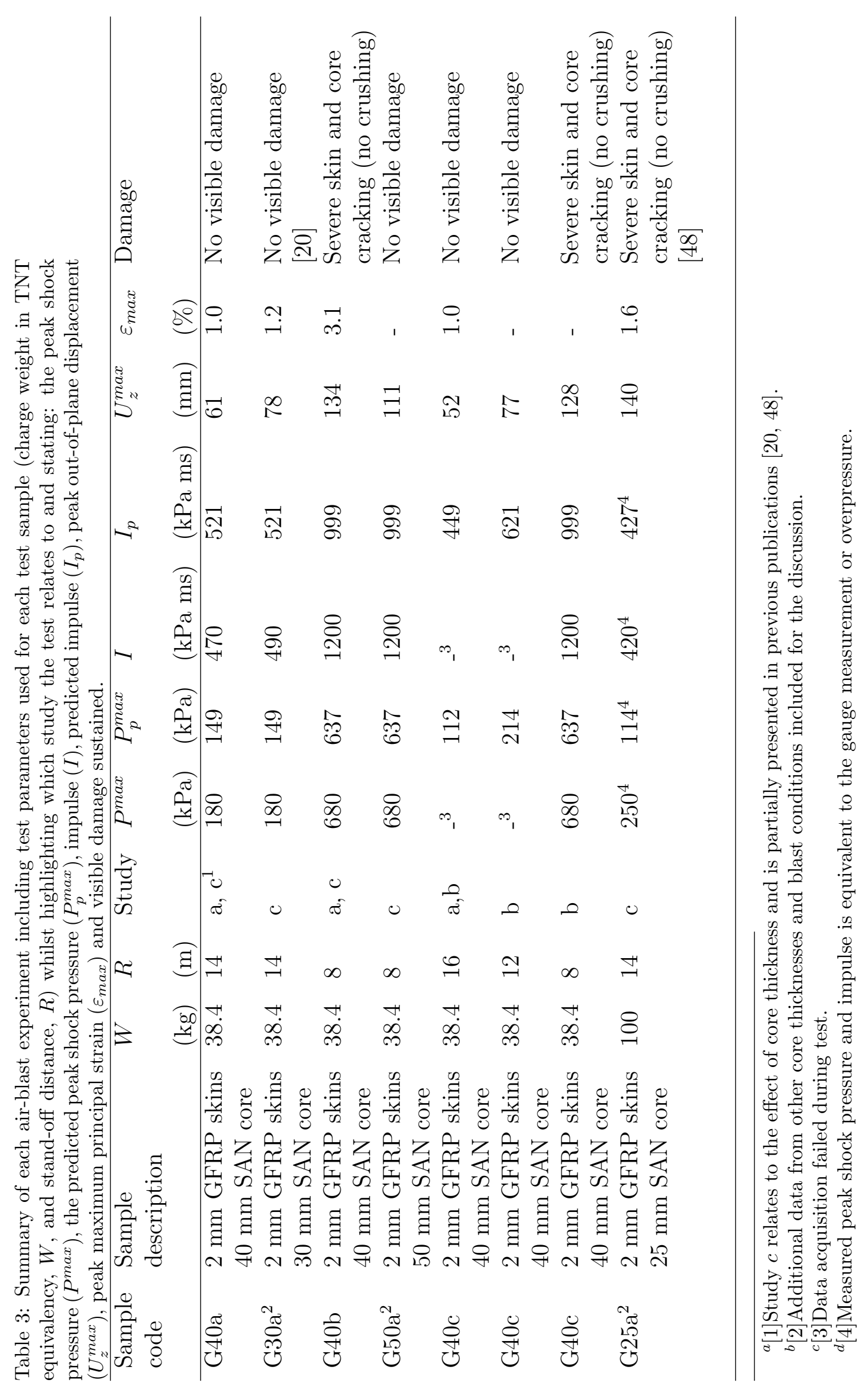




\subsection{Single blast loading of sandwich panels}

From samples in the set, three samples each $40 \mathrm{~mm}$ thick core (G40a, G40b and G40c) GFRP sandwich panels were subject to three separate 30 $\mathrm{kg}$ charge $\mathrm{C} 4$ explosions at $8 \mathrm{~m}, 14 \mathrm{~m}$ and finally $16 \mathrm{~m}$ stand-off distances. The effect of the reduced stand-off distance and the resultant different blast loading on target response is clear. As well as the response of the face-sheet material, the influence on support conditions has been highlighted. The increase of reflected impulse from $449-1200 \mathrm{kPa} \mathrm{ms}$, will naturally cause a greater degree of deformation of a given target of the same construction. The rise above $\sim 500 \mathrm{kPa}$ ms proved to be the threshold for damage initiation in this target. The nature of the failure seemed to be influenced by the deformation of the support structure. This is a key aspect of blast resistant design. The support structure can aid the capability of the target to absorb the blast energy. From simple structural response calculations taken from reference [12] it is seen that the strain energy absorbed by the target is proportional to the square of the central deflection. If the supports are allowed to move to some degree, then the overall deflection of the target would reduce due to this damping effect at the boundary. There are a number effects of such support conditions. Firstly the material is allowed to respond over a longer time period but secondly the magnitude of this strain energy acquired by the structure reduces in the face-sheets. For the final blast in this series $30 \mathrm{~kg} \mathrm{C} 4$ at $8 \mathrm{~m}$, the panel suffered skin cracking and core shear failure. The bias of the central support of the fixture caused an exaggerated strain to act towards the edge where failure was eventually observed. However when the charge was moved from $14 \mathrm{~m}$ to $8 \mathrm{~m}$, the impulse more than doubled, but the elastic deformation in the support did not increase accordingly or sufficiently. The deflections at the boundary were in the region of $1 / 3$ of the central deflection for the blast at $8 \mathrm{~m}$ stand-off compared to $1 / 2$ and higher for the blasts at $14 \mathrm{~m}$ and $16 \mathrm{~m}$. Therefore, the strain energy going into the sandwich material was significantly higher in this final blast (at $8 \mathrm{~m}$ ), with insufficient damping at the boundaries to absorb the blast energy without the target incurring damage. $U_{z}^{\max }$ was seen to increase in proportion to the impulse (see Figure 6), from 52-134 mm for a rise in impulse from 449$1200 \mathrm{kPa}$ ms. This was previously shown for GFRP-aluminium laminates in reference [23] and was expected given the mode of failure/response did not change until part way through the test at $8 \mathrm{~m}$. When the mode of deformation changes it is accompanied by a change in resistance function (the function that defines the response of a target to a given load). This 
certainly differs from static scenarios to dynamic and impulsive load cases. It also changes when the mode of deformation changes and vice versa, as this influences how the sample sustains moments (or flexure). A change there would affect the $U_{z}^{\max }$ that is attained and the nature of the deformation (shape function). Therefore here no changes were observed so a linear trend was observed for these three tests between $U_{z}^{\max }$ and $I$. In addition to these $40 \mathrm{~mm}$ core specimens, data is also included for $25-50 \mathrm{~mm}$ cores subject to blasts ranging from 38.4-100 kg TNT equivalent and presented in Table 3. This data is included from historical and unpublished data to extend the discussion on scaled deformation versus loading.

\subsection{Results of the finite element analysis}

The maximum deflection results are shown alongside the loading data in Table 4 . The results show that the model was able to reproduce the experimental maximum deflection results closely.

Table 4: Maximum deflection results for the FEA models used in the study compared to sample experimental data, where charge weight in TNT equivalency, $W$, stand-off distance, $R$, the peak shock pressure measured in the model $\left(P_{F E A}^{\max }\right)$, the peak shock pressure $\left(P^{\max }\right)$, impulse measured in the model $\left(I^{F E A}\right)$, impulse $(I)$, peak out-of-plane displacement measured in the model $\left(U_{z, F E A}^{\max }\right)$, peak out-of-plane displacement $\left(U_{z}^{\max }\right)$ are given.

\begin{tabular}{|c|c|c|c|c|c|c|c|c|}
\hline Model & $\begin{array}{l}W \\
(\mathrm{~kg})\end{array}$ & $\begin{array}{l}R \\
(\mathrm{~m})\end{array}$ & $\begin{array}{l}P_{F E A}^{m a x} \\
(\mathrm{kPa})\end{array}$ & $P^{\max }$ & $\begin{array}{l}I^{F E A} \\
(\mathrm{kPa} \mathrm{ms})\end{array}$ & $\begin{array}{l}I \\
(\mathrm{kPa} \mathrm{ms})\end{array}$ & $\begin{array}{l}U_{z, F E A}^{\max } \\
(\mathrm{mm})\end{array}$ & $\begin{array}{l}U_{z}^{\max } \\
(\mathrm{mm})\end{array}$ \\
\hline 1 & 38.4 & 16 & 110 & 112 & 455 & 449 & 48 & 52 \\
\hline 2 & 38.4 & 15 & 126 & $\mathrm{~N} / \mathrm{A}$ & 493 & $\mathrm{~N} / \mathrm{A}$ & 55 & $\mathrm{~N} / \mathrm{A}$ \\
\hline 3 & 38.4 & 14 & 148 & 180 & 544 & 490 & 61 & 61 \\
\hline 4 & 38.4 & 13 & 170 & $\mathrm{~N} / \mathrm{A}$ & 573 & $\mathrm{~N} / \mathrm{A}$ & 68 & $\mathrm{~N} / \mathrm{A}$ \\
\hline 5 & 38.4 & 12 & 202 & 214 & 618 & 621 & 76 & $77^{1}$ \\
\hline 6 & 38.4 & 11 & 251 & $\mathrm{~N} / \mathrm{A}$ & 692 & $\mathrm{~N} / \mathrm{A}$ & 83 & $\mathrm{~N} / \mathrm{A}$ \\
\hline 7 & 38.4 & 10 & 337 & $\mathrm{~N} / \mathrm{A}$ & 820 & $\mathrm{~N} / \mathrm{A}$ & 95 & $\mathrm{~N} / \mathrm{A}$ \\
\hline 8 & 38.4 & 9 & 447 & $\mathrm{~N} / \mathrm{A}$ & 939 & $\mathrm{~N} / \mathrm{A}$ & 113 & $\mathrm{~N} / \mathrm{A}$ \\
\hline 9 & 38.4 & 8 & 634 & 680 & 1260 & 1200 & 132 & $134^{2}, 128$ \\
\hline 10 & $38.4^{3}$ & 14 & 148 & 180 & 544 & 490 & 75 & 78 \\
\hline 11 & $38.4^{4}$ & 14 & 148 & $\mathrm{~N} / \mathrm{A}$ & 544 & $\mathrm{~N} / \mathrm{A}$ & 48 & $\mathrm{~N} / \mathrm{A}$ \\
\hline 12 & $38.4^{4}$ & 8 & 634 & 680 & 1260 & 1200 & 117 & 111 \\
\hline
\end{tabular}


The core was damaged in several models when the stand-off was below $12 \mathrm{~m}$. In all cases core elements near one of the panel corners were damaged first. This was realistic, as those were the areas where the highest stress concentrations would be formed during the deformation. However, the FEA software used was not able to proceed with the analysis once these initial failures were formed, causing the computation to stop. Therefore, it was not possible to analyse the final damage locations with the simple models used. Together with the deflection results, this also showed that the damage properties used for the skins did not affect the final simulation results, as failures were localised and expected within just a few test conditions. This style of models were therefore appropriate for the purpose of obtaining overall view of the dynamics. Further work is required to explore damage propagation and accumulation in detail.

The predicted maximum deflections though were all accurate, with maximum errors of $8 \%$ of the experimental results in the least accurate result and within $3 \%$ in all other cases. A typical deflection time history is shown in Figure 11. The deflected shape was similar to that observed in the experiments. In the first few milliseconds the panel appears to deform symmetrically. However, in the latter part of the deformation the symmetry is lost due to the different boundary support conditions on the panel edges. The period of vibration was lower than the recorded one, however this did not seem to significantly affect the final overall observation of interest which was peak deflection.

These similarities implied that the results of the parametric study could be employed to determine the relation between the loading (impulse, pressure) and the central panel deflection in the range considered. The results, together with the available experimental points, are plotted in Figure 12. These results showed that the maximum deflection increases near linearly with increasing impulse applied to the system. Equally when analysing the pressure data a near linear trend is observed. It should be noted that once again due to the consistent mechanism of deformation and non-catastrophic failure occurring, such a simple trend may be observed in line with linear momentum considerations described earlier.

\subsection{Multiple blast loading of sandwich panels}

From these experiments, it is clear that these marine structures are capable of sustaining far-field blasts of this nature. Moreover comparing the visible damage and $U_{z}^{\max }$ of this panel G40c and that of panel G40b, which 

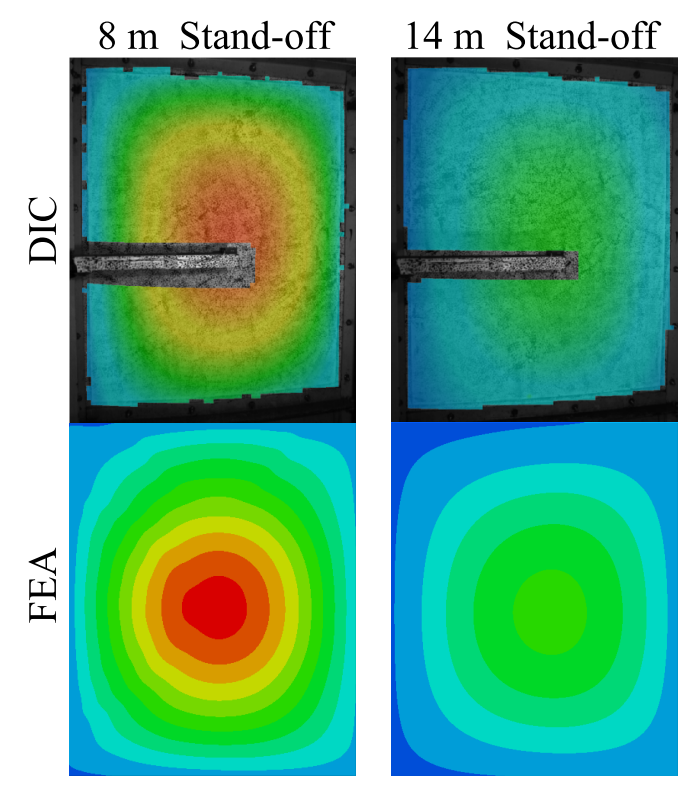

\section{$16 \mathrm{~m}$ Stand-off}
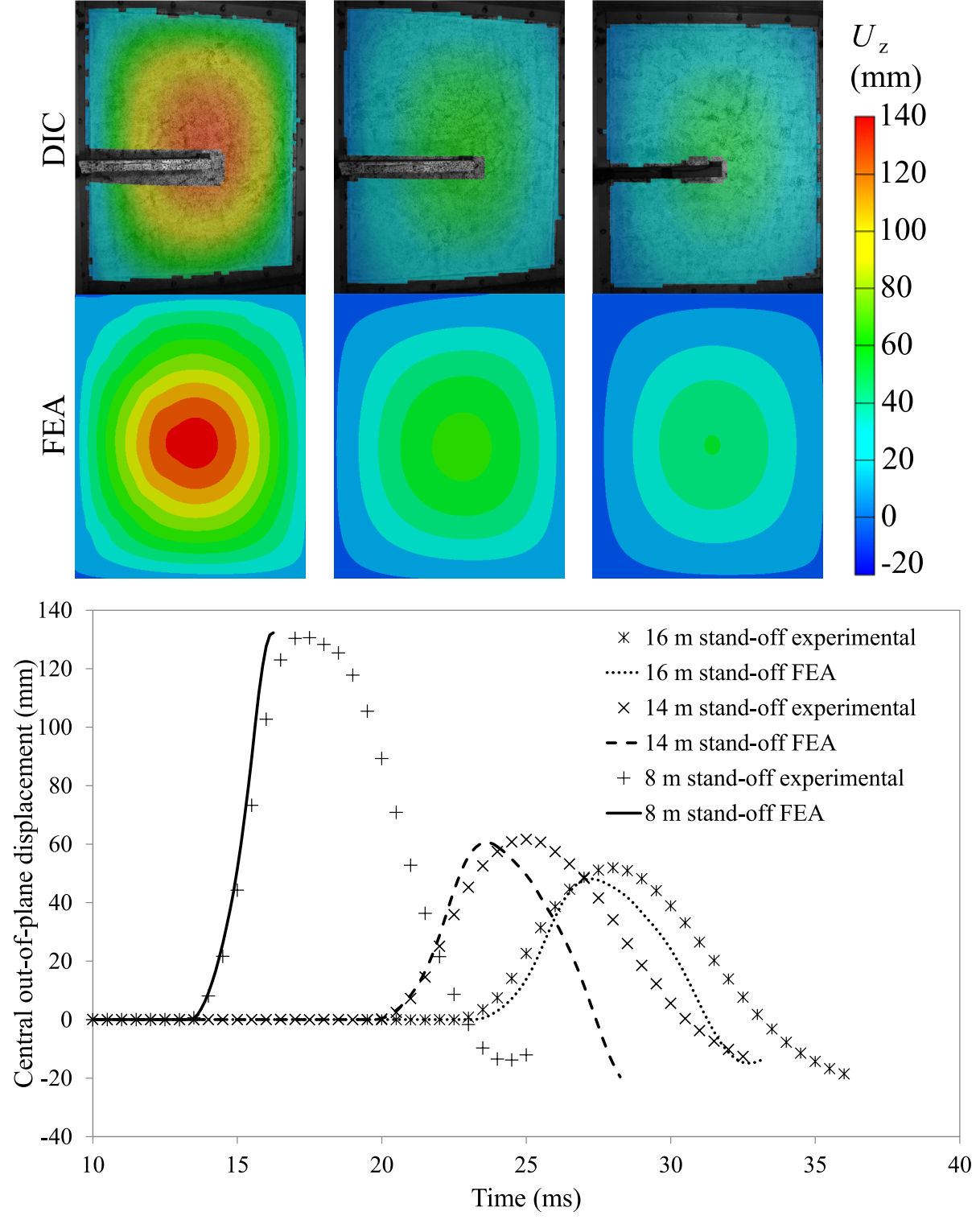

Figure 11: A summary of the experimental and FEA results. FEA data presented until the point of failure in the graphs.

were both subject to a blast of $30 \mathrm{~kg} \mathrm{C} 4$ at $8 \mathrm{~m}$, the results seem promising for multiple blast impacts.

$U_{z}^{\max }$ for G40b was $134 \mathrm{~mm}$ compared to G40c, which deflected to a max- 

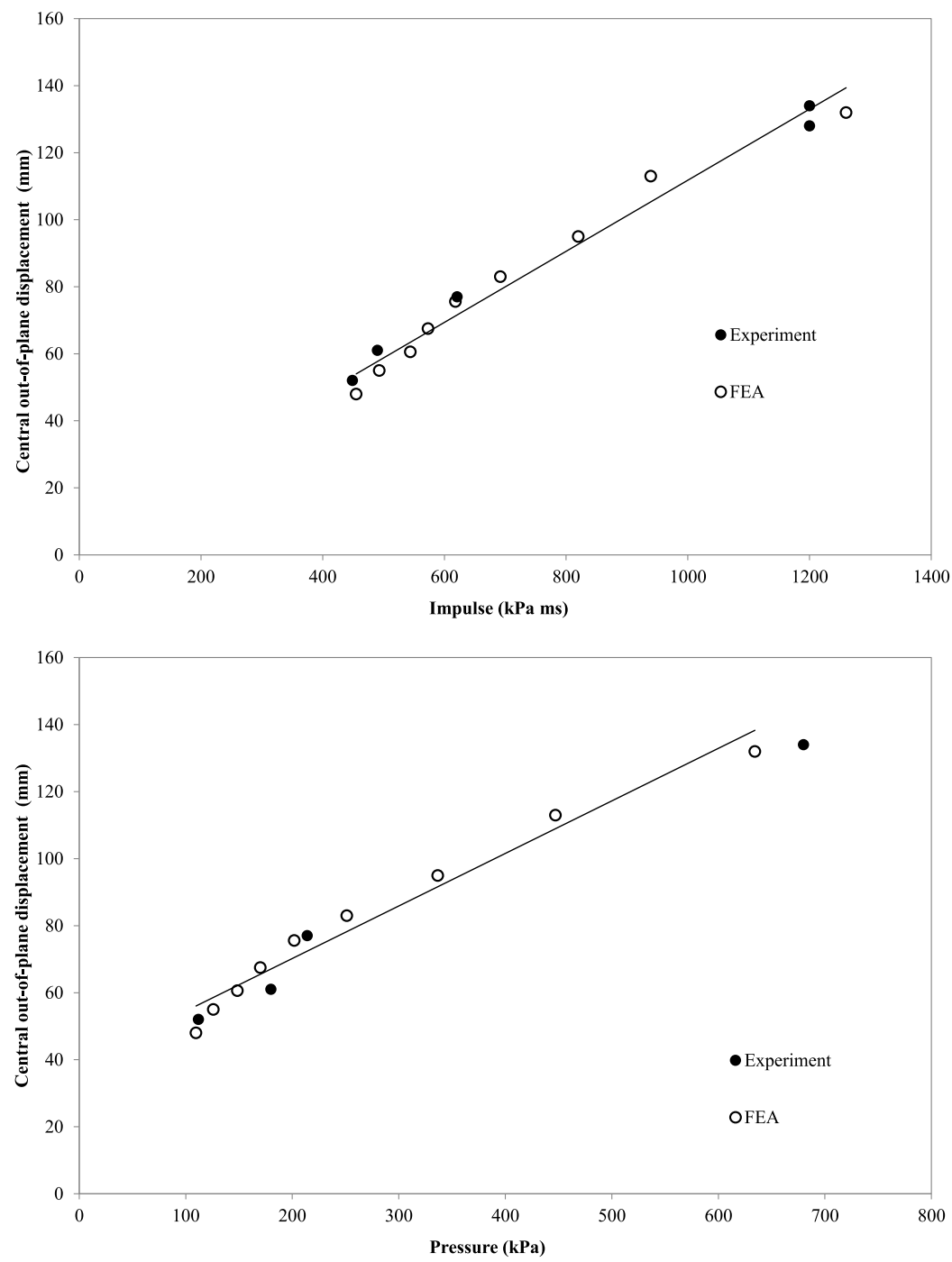

Figure 12: Comparison of experimental data with FEA for central out-of-plane displacement versus impulse and pressure of explosive threat.

imum distance of $128 \mathrm{~mm}$. This was after two previous blasts at $16 \mathrm{~m}$ and 12 $\mathrm{m}$ stand-off distances. However, the peak measurements indicate a reduced $U_{z}^{\max }$ for G40c. In no way is it being implied that the strength of the target improved after two blasts. The fact that G40c has sustained two blasts may have caused minor core damage as discussed, which has reduced the stiffness 
of the target. This would provide a less rigid obstacle for the blast to work against and could also give the skins more time to respond to the impulse. The rise time to $U_{z}^{\max }$ was observed to be $0.4 \mathrm{~ms}$ slower in G40c compared to G40b, perhaps due to this reduced stiffness. However these differences are too small to consider further (without repeat experimentation). The main point to arise from this is that the same magnitude or range of $U_{z}^{\max }$ was attained by both blast scenarios. Therefore even after blasts with $I$ in the range of $449-622 \mathrm{kPa}$ ms the apparent blast resistance of such a structure remains that of an un-blasted structure. Of course other blast scenarios may not achieve such results. Therefore further investigation would be needed to define such limits of acceptable damage prior to some design threshold blast load to still be resisted. Furthermore other design criteria, such as residual strength, may render G40c out-of-service after the $1^{\text {st }}$ blast, due to insufficient static load bearing capability.

\subsection{Scaled response of sandwich materials}

Analysing the deflection data for all samples from Table 3, a scaled response was derived for each specimen according to the sample dimensions. Equivalent flexural rigidity was calculated based on Ref.[49] for sandwich structures and used geometry and material data presented earlier in section 1.1. Data from different core thickness experiments were included, taken partly from published data $[20,38]$ to add to the numbers of tests included in this discussion. Figure 13 shows that trends remain consistent in spite of scaling between thicker and thinner specimens and larger/smaller explosive detonations. This is due to consistency of failure mechanisms once again from test to test i.e. deformation remained in the same regime across all tests.

\section{Conclusions}

Blast mitigation has been demonstrated for lightweight composite sandwich materials as related to full-scale marine and other structures and wellinstrumented data has been obtained. Large-scale blast testing has proved that full-field displacement and in-plane strain data can be reliably obtained for composite sandwich panels secured around their edge during explosive events. Detailed deformation maps were obtained by both using DIC under extreme shock loading conditions and by point measurements using a laser

gauge system. Several studies were conducted, which showed a number of real scenarios for naval structures, such as multiple blast impacts as well as 


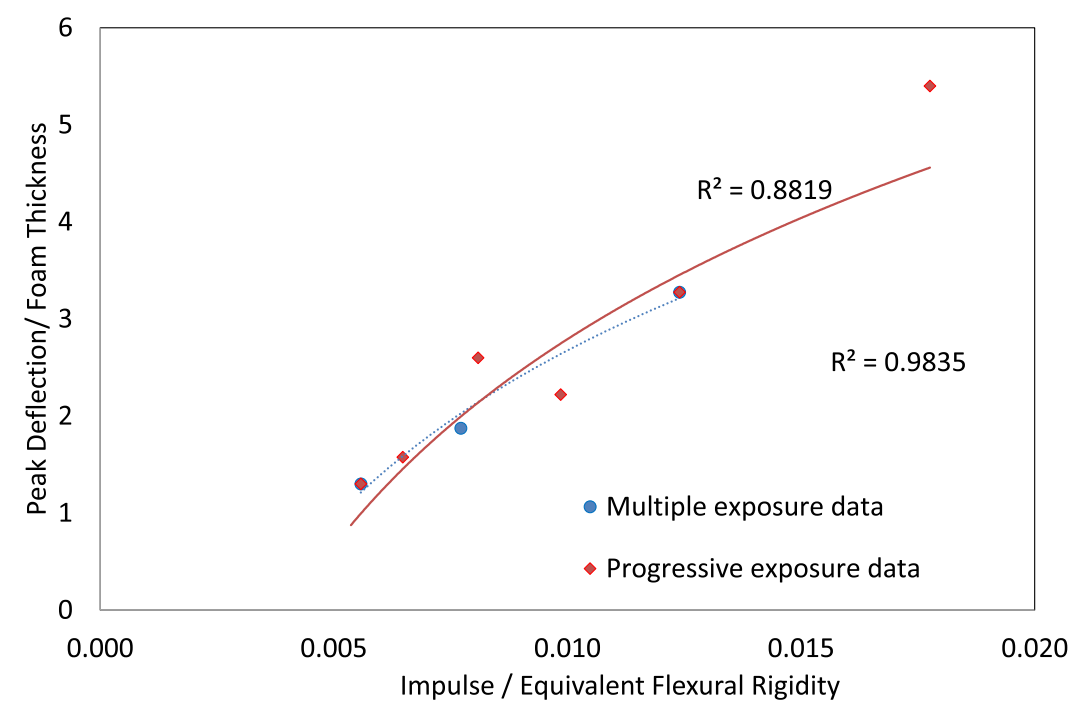

Figure 13: Plot of peak deflection, $U_{z}^{\max }$, divided by core thickness against impulse, $I$, divided by the equivalent flexural rigidity for each target.

a number of different intensity blast impacts on a given structure. Near linear trends were observed in terms of proportional displacement to increased blast load even when the same target was subject to multiple blasts, due to deformation and failure mechanisms remaining consistent within this study. Each of these experiments have shown that the modes of failure are front-face dominated compared to the underwater blasts, which involved both front and back face failures being observed [38]. The modes of core failure were seen to change from compressive to shear failure, leading to skin-to-skin core shear failures in blasts with $I$ above approximately $500 \mathrm{kPa}$ ms due to the excessive shear stresses causing crack initiation early on in the target response.

This full-field deformation and strain data provides for detailed validation of finite element models of large-scale explosive loading of composite sandwich panels. These data add to that already presented in [20] and [38]. These provide invaluable full-scale test data for blast resistant design.

\section{Acknowledgements}

Much appreciated is the strong support received from Dr Yapa Rajapakse of the Office of Naval Research (ONR N00014-08-1-1151) in particular for Hari Arora. We also appreciate useful discussions with ONR funded col- 
leagues and other researchers in the field of blast loading of composites. We also much appreciate the assistance from Dr P.A. Hooper during the blast experiments. We also acknowledge the Metropolitan Police and CPNI for use of the test cubicles and other equipment, GL-group for the use of their facilities and support on site, SP Gurit and PE Composites for provision of materials and GOM UK for support and access to latest DIC equipment during the analysis of the air-blast trial data. Dr Hari Arora and Professor John P. Dear much appreciate sponsorship by the United States Office of Naval Research (ONR) and United States Office of Naval Research Global (ONRG) to allow them to present at the ONR International Workshop on the Explosive Blast Response of Naval Composite Materials and Structures at RMIT, Australia (6-8 April 2016), organised by Professor Adrian Mouritz and Dr Yapa Rajapakse, where some of these research findings were described.

\section{References}

[1] N. Gardner, S. Gupta, E. Wang, and Arun Shukla. Blast Response of Sandwich Composites: Effect of Core Gradation, Pre-loading, and Temperature, pages 279-330. Springer New York, New York, NY, 2014.

[2] G. S. Langdon, W. J. Cantwell, Z. W. Guan, and G. N. Nurick. The response of polymeric composite structures to air-blast loading: a stateof-the-art. International Materials Reviews, 59(3):159-177, 2014.

[3] Weimin Nian, Kolluru V.L. Subramaniam, and Yiannis Andreopoulos. Experimental investigation on blast response of cellular concrete. International Journal of Impact Engineering, 96:105 - 115, 2016.

[4] Hua Zhu and Sanjeev K. Khanna. Dynamic response of a novel laminated glass panel using a transparent glass fiber-reinforced composite interlayer under blast loading. International Journal of Impact Engineering, 89:14 - 24, 2016.

[5] P. Del Linz, P.A. Hooper, H. Arora, D. Smith, L. Pascoe, D. Cormie, B.R.K. Blackman, and J.P. Dear. Reaction forces of laminated glass windows subject to blast loads. Composite Structures, 131:193 - 206, 2015.

[6] Huon Bornstein, Shannon Ryan, and Adrian Mouritz. Physical mechanisms for near-field blast mitigation with fluid containers: Effect of 
container geometry. International Journal of Impact Engineering, 96:61 $-77,2016$.

[7] D. Karagiozova, G.S. Langdon, G.N. Nurick, and T. Niven. The influence of a low density foam sandwich core on the response of a partially confined steel cylinder to internal air-blast. International Journal of Impact Engineering, 92:32 - 49, 2016. Impact Loading on Lightweight Structures.

[8] G.S. Langdon, W.C. Lee, and L.A. Louca. The influence of material type on the response of plates to air-blast loading. International Journal of Impact Engineering, 78:150 - 160, 2015.

[9] Shengrui Lan, Tat-Seng Lok, and Leonard Heng. Composite structural panels subjected to explosive loading. Construction and Building Materials, 19(5):387-395, 2005.

[10] P.A. Buchan and J.F. Chen. Blast resistance of frp composites and polymer strengthened concrete and masonry structures a state-of-theart review. Composites Part B: Engineering, 38(56):509 - 522, 2007.

[11] S. Lan and L. Heng. Structures Under Shock and Impact VII. WIT Press, 2002.

[12] P.D. Smith and J.G. Hetherington. Blast and ballistic loading of structures. Butterworth Heinmann, 1994.

[13] R.D. Ambrosini A.C. Jacinto and R.F. Danesi. Experimental and computational analysis of plates under air blast loading. International Journal of Impact Engineering, 25(10):927-947, 2001.

[14] M.S. Hoo Fatt and L. Palla. Analytical modeling of composite sandwich panels under blast loads. Journal of Sandwich Structures and Materials, 11(4):357-380, 2009.

[15] S.B. Menkes and H.J. Opat. Tearing and shear failure in explosively loaded clamped beams. Experimental Mechanics, 13(11):480-486, 1973.

[16] G.N. Nurick and J.B. Martin. Deformation of thin plates subject to impulsive loading - a review, part ii: Experimental studies. International Journal of Impact Engineering, 8(2):171-186, 1989. 
[17] S. Peles A. Neuberger and D. Rittel. Scaling the response of circular plates subjected to large and close-range spherical explosions. part i: Air-blast loading. International Journal of Impact Engineering, 34(5):859-873, 2007.

[18] S. Peles A. Neuberger and D. Rittel. Scaling the response of circular plates subjected to large and close-range spherical explosions. part ii: buried charges. International Journal of Impact Engineering, 34(5):874882, 2007.

[19] Vikrant Tiwari, Michael A. Sutton, S.R. McNeill, Shaowen Xu, Xiaomin Deng, William L. Fourney, and Damien Bretall. Application of 3d image correlation for full-field transient plate deformation measurements during blast loading. International Journal of Impact Engineering, 36(6):862-874, 2009.

[20] P.A. Hooper H. Arora and J. P. Dear. Dynamic response of full-scale sandwich composite structures subject to air-blast loading. Composites Part A, 42:1651-1662, 2011.

[21] G.N. Nurick M.D. Olsson and J.R. Fagnan. Deformation and rupture of blast loaded square plates - predictions and experiments. International Journal of Impact Engineering, 13(2):279-291, 1993.

[22] M.E. Gelman G.N. Nurick and N.S. Marshall. Tearing of blast loaded plates with clamped boundary conditions. International Journal of Impact Engineering, 18(7-8):803-827, 1996.

[23] W.J. Cantwell G.S. Langdon and G.N. Nurick. The blast response of novel thermoplastic-based fibre-metal laminates some preliminary results and observations. Composites Science and Technology, 65:861872, 2005 .

[24] G.N. Nurick M.C. Simmons W.J. Cantwell G.S. Langdon, S.L. Lemanski and G.K. Schleyer. Behaviour of fibremetal laminates subjected to localised blast loading: Part i experimental observations. International Journal of Impact Engineering, 34:1202-1222, 2007.

[25] G.S. Langdon, C.J. von Klemperer, B.K. Rowland, and G.N. Nurick. The response of sandwich structures with composite face sheets and 
polymer foam cores to air-blast loading: Preliminary experiments. Engineering Structures, 36:104-112, 2012.

[26] H.S. Turkmen and Z. Mecitoglu. Nonlinear structural response of laminated composite plates subjected to blast loading. AIAA, 37(12):16391647, 1999.

[27] H.S. TRKMEN. Structural response of laminated composite shells subjected to blast loading: Comparison of experimental and theoretical methods. Journal of Sound and Vibration, 249(4):663 - 678, 2002.

[28] Abiy F. Tasissa, Martin Hautefeuille, John H. Fitek, and Raúl A. Radovitzky. On the formation of friedlander waves in a compressedgas-driven shock tube. Proceedings of the Royal Society of London A: Mathematical, Physical and Engineering Sciences, 472(2186), 2016.

[29] S. Mallon, B. Koohbor, A. Kidane, and M.A. Sutton. Fracture behavior of prestressed composites subjected to shock loading: A dic-based study. Experimental Mechanics, 55(1):211-225, 2015.

[30] Marcia A. Cooper, Michelle N. Skaggs, and Phillip L. Reu. High-Speed Stereomicroscope Digital Image Correlation of Rupture Disc Behavior, pages 19-26. Springer International Publishing, Cham, 2016.

[31] Theofano Eftaxiopoulou, Ashton Barnett-Vanes, Hari Arora, Warren Macdonald, Thuy-Tien N. Nguyen, Mako Itadani, Anna E. Sharrock, David Britzman, William G. Proud, Anthony M.J. Bull, and Sara M. Rankin. Prolonged but not short-duration blast waves elicit acute inflammation in a rodent model of primary blast limb trauma. Injury, 47(3):625 - 632, 2016.

[32] S.A. Tekalur, K. Shivakumar, and A. Shukla. Mechanical behavior and damage evolution in e-glass vinyl ester and carbon composites subjected to static and blast loads. Composites Part B: Engineering, 39(1):57-65, 2008.

[33] S.A. Tekalur, A.E. Bogdanovich, and A. Shukla. Shock loading response of sandwich panels with 3-d woven e-glass composite skins and stitched foam core. Composites Science and Technology, 69(6):736-753, 2009. 
[34] S.A. Tekalur, A. Shukla, and K. Shivakumar. Blast resistance of polyurea based layered composite materials. Composites Structures, 84(3):271-281, 2008.

[35] M. Jackson and A. Shukla. Performance of sandwich composites subjected to sequential impact and air blast loading. Composites Part B: Engineering, 2011. In Press.

[36] E.H. Wang and A. Shukla. Analytical and experimental evaluation of energies during shock loading. International Journal of Impact Engineering, 37(12):1188-1196, 2010.

[37] J. LeBlanc and A. Shukla. Dynamic response and damage evolution in composite materials subjected to underwater explosive loading: An experimental and computational study. Composite Structures, 93(3):10601071, 2010.

[38] P.A. Hooper H. Arora and J. P. Dear. The effects of air and underwater blast on composite sandwich panels and tubular laminate structures. Experimental Mechanics, 52:59-81, 2012.

[39] H. Arora, P.A. Hooper, P. Del Linz, H. Yang, S. Chen, and J.P. Dear. Modelling the behaviour of composite sandwich structures when subject to air-blast loading. The International Journal of Multiphysics, 6(3), 2012 .

[40] I.M. Daniel, E.E. Gdoutos, and Y.D.S. Rajapakse, editors. $M a-$ jor Accomplishments in Composite Materials and Sandwich Structures. Springer Netherlands, 1 edition, 2009.

[41] S. Abrate, B. Castani, and Y.D.S. Rajapakse, editors. Dynamic Failure of Composite and Sandwich Structures. Springer Netherlands, 1 edition, 2013.

[42] SP Gurit. Material data sheets. www.gurit.com, 2011.

[43] J.E. Slater. Selection of a blast-resistant grp composite panel design for naval ship structures. Marine Structures, 7(2):417 - 440, 1994.

[44] Dassault Systmes Simulia. Abaqus analysis manual. Providence, RI, version 6.13 edition, 2013. 
[45] Z. Hashin. Failure criteria for unidirectional fiber composites. Journal of Applied Mechanics, 47:329-334, 1980.

[46] V.L. Tagarielli, V.S. Deshpande, and N.A. Fleck. Prediction of the dynamic response of composite sandwich beams under shock loading. International Journal of Impact Engineering, 37(7):854 - 864, 2010.

[47] M. Kelly. Comparing the blast tolerance of different composite structures. Phd, Imperial College London, 2016.

[48] H. Arora, M. Kelly, A. Worley, A. Fergusson, P. Del Linz, P.A. Hooper, and J.P. Dear. Compressive strength after blast of sandwich composite materials. Phil. Trans. of The Royal Society A, 372, 2014.

[49] L.J. Gibson and M.F. Ashby. Cellular solids, structure and properties, Second ed. Cambridge University Press., 1997. 